\title{
The effect of using Flipped Learning on the level performance of some technical skills for beginners in volleyball
}

\section{Mohamed fathi ali mowafi}

Abstract of research:

This research aims to identify the effect of using Flipped Learning on the level performance of some technical skills for beginners in volleyball, and the researcher used the experimental approach. The researcher selected a sample of the research from students of the first boys group at the Faculty of Physical Education Mansoura University for the academic year (2016-2017 m) where their number reached (40)student, and the researcher concluded that there are statistically significant differences between the two dimensional measurements of both the control and experimental group in the level performance of some technical skills for beginners in volleyball under research in favor of the experimental group, and that the reverse learning method is one of the best learning methods that uses modern technology in teaching some Technical skills in volleyball (under research).

\section{Introduction and research problem:}

The scientific progress in our time has led to fundamental changes in various areas of life. The current age is the age of integration between computers and the human mind, and thus the educational system has witnessed movements calling for the development of education in terms of its goals, curricula and methods so that the learner can keep pace with development and the ability to live In an era of advanced technologies, and as a result of the rapid development in the field of computers and multimedia, educators saw the necessity of introducing them to the educational process as one of the educational developments calling for modernizing teaching and avoiding traditional methods and methods in education.

Brame, Cynthia J (2013) holds that Flipped Learning is one of the modern technical solutions to treat weak traditional learning and develop the level of thinking skills of students, and teaching Flipped Learning includes the use of technology to benefit from it in the educational process, so that the teacher can spend more time interacting, talking and discussing with Students in the class instead of giving lectures, where students watch short pictures and videos of lectures at home and keep the most time to discuss the content in the class under the supervision of the teacher, and according to Bloom's average classification, students investigate Flipped Learning the lower level of the 
cognitive domain (obtaining and absorbing knowledge) At home, focus on the higher level of the cognitive domain (application, analysis, synthesis, evaluation) at the time of the semester. (2)

Haitham Atef Hassan (2017) explains that the idea of reverse learning is based on the heart of the educational process. Instead of students receiving new concepts in the classroom and then returning home to perform homework in traditional education, the process fluctuates here as students in reverse learning receive new concepts of the lesson in Home by preparing the teacher for videos using auxiliary programs between 5-10 minutes, pictures and illustrations and sharing them on one of the websites or social networks, or their participation in a video or multimedia or educational games from electronic information sources, where students learn using these The strategy is new lesson concepts at home through modern technologies such as smartphones or portable computer devices, so students can repeat the video several times, to be able to understand the new concepts, and they can also accelerate the clip to override the parts that have been absorbed, so the individual differences between students are taken into consideration and an element disappears Boredom is replaced by an element of suspense and enjoyment of learning. (4:52)

Atef Abu Hamid Al-Sharman (2015) believes that Flipped Learning is the type of learning in which the usual class or lecture is transformed through available and appropriate technology into registered lessons that are placed on the Internet, so that students can access it outside the classroom to allow the field to do various activities and learn Active and optimal use of learning time in the classroom and under the supervision of the teacher to enrich the teaching and learning process.(1:11)

Through a review of some of the previous studies and scientific references that showed the importance of reverse learning in the educational process and the impact of its application on various stages of life, and from these studies: a study of Safa Ahmed Lotfy (2018) (8), a study by Nadia Hassan Zaghloul (2017) (7) Johnson (5) 2012 study, in addition to the teaching experiences of the researcher as a teacher of volleyball course at the Faculty of Physical Education in Mansoura University, who observed a lack of diversity in teaching methods and note the weak level of students in learning technical skills in volleyball, and not employing technological tools in the process In a significant way, a large number of teachers are still following the traditional method of teaching (explanation and model performance), and through research, reading, and extrapolation of previous studies within the limits of science - the researcher - and investigating the effect of the reversed learning method on the achievement of the physical education curriculum in general and the volleyball curriculum in particular, it has I found that these studies did not address the use of this method before in the field of volleyball, which gave the researcher a sense of the need to study the effect of this method on the process of learning some technical skills in volleyball and the use of 
some Modern technological means through the use of educational videos, images, read texts and other modern technologies and merging them with teaching methods in education in order to improve communication between the teacher and students inside and outside the classroom, which invited the researcher to try to identify the impact of using reverse learning on the level of some technical skills for beginners in the ball The Plane.

\section{Research objective:}

This research aims to identify the effect of using Flipped Learning on the level performance of some technical skills for beginners in volleyball.

\section{Research hypotheses :}

1. There are statistically significant differences between the pre and post measurement in the level performance of some technical skills for beginners in volleyball in favor of the dimensional measurement of the control group.

2. There are statistically significant differences between the pre and post measurement in the level performance of some technical skills for beginners in volleyball in favor of the dimensional measurement of the experimental group.

3. There are statistically significant differences between the two dimensional measurements of both the control and the experimental group in the level performance of some technical skills for beginners in volleyball under consideration in favor of the experimental group.

\section{Key words:}

Flipped Learning: Zhou, G Jiang (2014): defines inverted education as an educational technology that consists of two parts in the class in the form of interactive activities between students and the teacher and outside the class in the form of educational assignments. (10: 264)

\section{Search procedures:}

\section{Research Methodology :}

The researcher used the experimental method using the method of tribal / dimensional measurements of the two groups, one is experimental and the other is control.

\section{Research Society and Sample:}

\section{research community:}

The research community was chosen from the students of the first boys group at the Faculty of Physical Education, Mansoura University, who are registered in the college records for the academic year (2016-2017) and the number is (584) students. 


\section{The research sample:}

The researcher has chosen the technical research sample in an intentional manner from the first boys students in the Faculty of Physical Education, Mansoura University, for the academic year (2016-2017), and that the total number of the research sample is (55) students divided into (40) students Experimental group of (20) students, with a percentage of (36.36\%), and a control sample of (20) students, with a percentage of (36.36\%). An exploratory sample was selected, and their number reached (15) students, with a rate of $(27.28 \%)$.

\section{Conditions for selecting a sample:}

All members of the sample have a smart mobile phone equipped with an Internet loaded with Whatsapp.

\section{Moderation of the study sample distribution:}

The researcher has performed a moderate distribution between the individuals of the research sample in the main variables under investigation by calculating the convolution coefficient, and the coefficient of convolution ranges between $(+3,-3)$ and this gives a direct indication of homogeneity, and indicates that the data for each of the physical and skill variables are all homogeneous This indicates the homogeneity of the study group in the basic research variables.

\section{Equivalent research sample:}

The researcher has performed parity between the members of the experimental and control sample of the research before applying the program in the variables that may affect the results of the research and it was found that there were no statistically significant differences in the dimensional measurements of the experimental and control groups in the physical and skill variables under study, as the calculated " $\mathrm{t}$ " value is less Of the tabular value at the level of significance 0.05 , which indicates the equivalence of the two research groups in these variables.

\section{Data collection methods and tools:}

\section{First: The devices used:}

- Mobile phones with internet access, volley balls, volleyball court, cones, and adhesive tapes.

\section{Second: The tools used:}

\section{First: Physical tests: Attachment (1)}

The researcher has reviewed the previous scientific references, studies and research with the aim of identifying tests with high scientific treatments to measure the physical abilities of volleyball, and they were as follows (Zigzag running test to measure fitness, torso bending test in front of standing to 
measure flexibility, choosing vertical jump to measure ability, tensile test of dynamometer for measuring force, passing a volleyball on a wall for $(25 \mathrm{~s})$ to measure kinematic compatibility.

\section{Second: The Volleyball Skill Test: Attachment (2)}

(AAPHER test for bottom-up and up-top transmission, Clifton passthrough ball wall (30s) pass-through, AAPHER-pass-through wall to pass from top).

\section{Exploratory studies:}

\section{The first survey:}

- It was conducted from February 212017 to February 272017.

- The tests in question were codified as follows:

\section{First: Verify the tests:}

The researcher calculated the sincerity of the physical and skill tests under investigation using the differentiation sincerity by selecting a group of the first group students (15) students from the same research community and outside the exploratory sample and representing the non-distinct sample, and the distinct group of specialization students was chosen in the third group at the Faculty of Physical Education Mansoura University And it turned out that there are statistically significant differences between the distinct and non-distinct group since the calculated value of $(\mathrm{T})$ in all fields is greater than the value of the table $(\mathrm{T})$ at the significance level $(0.05)$, which confirms the validity of the tests, that is, they are sincere tests to measure the characteristics that have been developed For it.

\section{Second: The stability of the tests:}

The researcher has calculated the stability of the tests under research under research by applying the test and re-applying it to calculate the stability with a time difference of seven days between the two tests taking into account the uniformity of the same measurement conditions, and it was found that there is a statistically significant correlation between the first application and reapplication as the correlation coefficient values for the tests are greater than the value of ( $R$ ) The tabular at the level of significance 0.05 , which indicates the stability of the tests used in the research.

\section{The second survey:}

It was conducted in the period from 2/28/2017 to 2/3/2017 AD, and it was confirmed the validity of the place where the program will be applied, the validity of the tools and devices used in the measurements and the program, and the assistants' understanding of the procedures for measuring the tests as well as making sure how to record the results. 


\section{Suggested Program: Attachment (3)}

\section{First: The general objectives of the proposed program:}

The program aims to develop the proposed program using inverted education in order to improve some of the technical skills of students in volleyball.

\section{Second: The foundations for building the proposed program:}

The researcher based on building the proposed program for this study on the following foundations:

- Take into account the organization of activities within the unit to achieve continuity, sequence, integration, flexibility and clarity in identifying the most important duties of the unit and the ease and availability of capabilities, tools and devices used

- Providing the opportunity for participation and practice for each student at the same time.

\section{Availability of a safety and security factor.}

\section{Third: Program content:}

It is all the activities that the program contains that are planned and intended to be learned, and when choosing the content of the program must take into account its criteria, that it be of value and importance and benefit to improve skill performance, and the content is related to the objectives of the program, and it is important that it be characterized by inclusion, diversity, safety, integrity and continuity, Besides, the content must match the available capabilities.

The choice of content depends on the type of goal to be achieved, and it meets all the needs in a way that suits the needs and capabilities of students, and it is important to choose what is understood quickly, and the activities must be simplified and easy way, and take into account the characteristics of students, and the content should be within the existing capabilities and achieve opportunities Equal participation of all students, and the content should be flexible and adjustable.

\section{Fourth: The time period for implementing the proposed program:}

The time period for applying the program was determined as follows: the number of educational program (8) weeks, the total number of educational units (8) units by the unit of educational unit per week, the time of the educational units of the unit (two hours) applied according to the internal regulations of the college, with the total total time of the educational program (16) hours.

\section{Tribal measurements:}

The pre-measurement was conducted for all members of the research sample in the period 3/5/2017 to 3/6/2017 AD. 


\title{
Basic study:
}

The proposed program was implemented on the members of the experimental and control group, as it took (8) weeks from 3/7/2017 to corresponding to $4 / 25 / 2017$.

\section{Dimensional measurements:}

Dimensional measurement was carried out for all members of the research sample in the period from 4/26/2017 to Thursday corresponding to 4/27/2017.

\section{Statistical treatments:}

Statistical processing by computer using SPSS \& EXCEL programs. In order to achieve the goals of research and hypothesis testing, the researcher used the following statistical treatments:

- mean.

- Median.

- standard deviation.

- Correlation.

- Skewness.

- Test "t" .

- Change percentag.

\section{Discussion of the results.}

The results of the first hypothesis:

\author{
Table (8)
}

An indication of the differences between the pre and post measurements of the control group in the skill variables

\begin{tabular}{c|c|c|c|c|c|c|c}
\hline \multirow{2}{*}{ the exams } & \multicolumn{2}{|c|}{ Pre } & \multicolumn{2}{c|}{ post } & $\begin{array}{c}\text { Mean } \\
\text { Different }\end{array}$ & t value & $\begin{array}{c}\text { Change } \\
\text { percentag }\end{array}$ \\
\cline { 2 - 8 }$n$ & Mean & sd & Mean & sd & -10.138 & $12.479 *$ & $\% 86.687$ \\
\hline underhand pass & 11.695 & 0.249 & 21.833 & 2.085 & 6.201 & $* 8.657$ & $\% 80.627$ \\
\hline overhand pass & 7.691 & 0.160 & 13.892 & 0.268 & 6.630 & $9.832 *$ & $\% 41.887$ \\
\hline underhand serve & 20.603 & 0.228 & 29.233 & 3.683 & 8.6372 & $10.891 *$ & $\% 82,800$ \\
\hline $\begin{array}{c}\text { over hand or } \\
\text { tennis serve }\end{array}$ & 9.628 & 0.186 & 17,600 & 1.328 & 7.972 \\
\hline
\end{tabular}

* The value of the tabular " $\mathrm{T}$ " at the level of significance $0.005=\mathbf{2 . 0 9 3}$

It is clear from Table (8) that there are statistically significant differences between the pre and post measurement of the control group in favor of the post measurement in the skill variables where the value of $(\mathrm{T})$ calculated in all fields is greater than the value of the table (T) at the significance level (0.05) in favor of the post measurement. 
The researcher attributes these differences to the control group in the dimensional measurements to the traditional methods of education and based on the explanation and the presentation of various educational materials and the good students' listening, and taking notes that will remind them of what the teacher gave them during the presentation, explanation and clarification so that students at the end of the lesson are required to make costs and homework And those practices are repeated daily and the researcher should monitor the progress of students by evaluating their performance of costs and homework, and this has helped to improve their performance in some skills but not to the desired level.

This is consistent with the study of Nadia Hassan Zaghloul (2017) that there are statistically significant differences between the pre and post measurements in the skill variables of the control group in favor of the post measurement. (7)

Thus, the first hypothesis is validated "there are statistically significant differences between pre and post measurement in the level of some technical skills for beginners in volleyball in favor of the post-measurement of the control group."

The results of the second hypothesis, which states:

Table (9)

An indication of the differences between the pre and post measurements of the Experimental group in the skill variables

$\mathbf{n}=\mathbf{2 0}$

\begin{tabular}{c|c|c|c|c|c|c|c}
\multirow{2}{*}{ the exams } & \multicolumn{2}{|c|}{ Pre } & \multicolumn{2}{c|}{ post } & $\begin{array}{c}\text { Mean } \\
\text { Different }\end{array}$ & t value & $\begin{array}{c}\text { Change } \\
\text { percentag }\end{array}$ \\
\cline { 2 - 8 } & Mean & sd & Mean & sd & 14.307 & $15.742 *$ & $\% 112.423$ \\
\hline underhand pass & 12.726 & 0.250 & 27.033 & 2.539 & 1.63 \\
\hline overhand pass & 8.361 & 0.190 & 19.553 & 1.638 & 11.192 & $11.625^{*}$ & $\% 133.860$ \\
\hline underhand serve & 19.545 & 0.263 & 35.266 & 5.212 & 15.721 & $11.668 *$ & $\% 80.435$ \\
\hline $\begin{array}{c}\text { over hand or } \\
\text { tennis serve }\end{array}$ & 10.545 & 0.526 & 24.166 & 1.743 & 13.621 & $19.524 *$ & $\% 129.170$ \\
\hline
\end{tabular}

* The value of the tabular "T" at the level of significance $0.05=2.093$

It is clear from Table (9) that there are statistically significant differences between the pre and post measurement of the experimental group in favor of the post measurement in the skill variables where the value of $(\mathrm{T})$ calculated in all fields is greater than the value of the table $(\mathrm{T})$ at the level of significance $(0.05)$ in favor of post measurement .

The researcher attributes this to the fact that using inverse teaching ensures the optimal use of time and provides appropriate support for students that find it difficult to learn skills and raise their educational level, and that inverted teaching helps students to repeat the lesson more than once based on their individual differences, and this would reduce anxiety Students while 
performing motor skill, in addition to having the opportunity to take advantage of student activity effectively, and skills training within the lecture collaboratively among students under the guidance and guidance of the teacher.

This is consistent with what Khan et al. (2013) indicated. That this model enables the teacher to direct his students to implement specific educational projects, which helps them learn the educational content in greater depth and takes them to the level of skills training and makes the possibility of receiving feedback from the teacher something possible and more effective, and enables the teacher to spend more time in training His students help them develop and build their skills and guide them to learn through the implementation of various educational projects. (6: 162)

The researcher also attributes the results to the effectiveness of the proposed program using reverse learning in developing the targeted skills of students, as it pays great attention to the realistic practice of what is taught, and increases the time allocated to practical application, and emphasizes that the application takes place in a controlled and controlled context by the researcher who ensures His presence and face-to-face interaction with students during the practical application in that all learners apply and practice and accomplish what is required of them from practical tasks, as the activities were designed by the researcher to increase the ability of students to master the practical skills that they are training in a large way and push them positively towards doing everything They strive to reach the best educational product possible.

Estes et al. (2014) indicated that adding active learning strategies to the reverse learning model is a guarantee towards achieving good results in learning, and the positive interaction of learners that results from employing these strategies is responsible towards achieving the difference between the reverse learning model and the traditional learning system by improving Different learning outcomes and the desired degree of proficiency. (3: 97)

The results of this study are consistent with the study of Safa Ahmed Lotfy (2018), whose results indicated an improvement in the level of technical performance form of passing skills, level of cognitive achievement, opinions, and sentimental impressions of students of the experimental group used Flipped Learning. (8)

Thus, the second hypothesis is validated "There are statistically significant differences between the pre and post measurement in the level of some technical skills for beginners in volleyball in favor of the dimensional measurement of the experimental group."

The results of the third hypothesis, which states: 
Table (10)

An indication of the differences between the two dimensions of the experimental and control groups in the skill variables

\begin{tabular}{|c|c|c|c|c|c|c|c|}
\hline \multirow{2}{*}{ he exams } & \multicolumn{2}{|c|}{$\begin{array}{c}\text { Experimental } \\
\text { group }\end{array}$} & \multicolumn{2}{|c|}{ Control group } & \multirow[t]{2}{*}{$\begin{array}{c}\text { Mean } \\
\text { Different }\end{array}$} & \multirow{2}{*}{ t value } & \multirow{2}{*}{$\begin{array}{l}\text { Change } \\
\text { percentage } \\
\text { differences }\end{array}$} \\
\hline & Mean & sd & Mean & sd & & & \\
\hline underhand pass & 27.033 & 2.539 & 21.833 & 2.085 & 5.200 & $13.366 *$ & $\% 25.737$ \\
\hline overhand pass & 19.553 & 1.638 & 13.892 & 0.268 & 5.661 & $12.633 *$ & $\% 53.233$ \\
\hline underhand serve & 35.266 & 5.212 & 29.233 & 3.683 & 6.033 & $9.266 *$ & $\% 38,548$ \\
\hline $\begin{array}{l}\text { over hand or } \\
\text { tennis serve }\end{array}$ & 24.166 & 1.743 & 17,600 & 1.328 & 6.566 & $9.400 *$ & $\% 46.370$ \\
\hline
\end{tabular}

* The value of the " $T$ " tabular at the level of significance $0.05=2.042$

From Table (10), it is clear that there are statistically significant differences in the dimensional measurements of the experimental groups and the control in the skill variables under consideration in favor of the experimental group measurement. Whereas, the calculated value of " $\mathrm{T}$ " is greater than its tabular value at the level of significance 0.05 .

The researcher attributes the experimental group's superiority in the skill variables to the proposed program using Flipped Learning, which helped to accomplish the targeted tasks in a frank and detailed way, so that it dealt with the main and subsidiary skills and performances under each sub-skill, which helped them to properly understand the skill aspect.

This is consistent with what Schell (2013) indicated, which indicated the excellence of reverse learning by providing an active learning environment in which learners have detailed information to achieve a full understanding of the educational content, and students work together under the supervision and guidance of the teacher so that learners who have reached the correct understanding are directed Concepts and all aspects of knowledge of the educational content targeted to study in helping colleagues who did not reach that to remove the conceptual confusion and correct it, which ensures the achievement of correct understanding and increase the level of achievement for all students. (9: 81)

The researcher also attributes these results to the fact that Flipped Learning has led to an increase in students 'sense of teaching themselves and in seeking to excel by making their best efforts to reach the highest level of quality in their performance of motor skills, and that the collective and active work that characterized Flipped Learning is one of the advantages that may She contributed to reaching this positive result and the main goal of the reverse learning model is that it works to make good use of the technological structure and multiple digital information sources that are now among the main sources of learning, in the context of promoting principles of active learning by focusing on the interaction of learners and their activity in an environment Learning and 
solving problems or seeking knowledge on their own, which helped students of the experimental group to develop the skills in question.

This is what Atef Al-Sharman (2015) pointed out that Flipped Learning brings the learner to the higher levels of knowledge such as application, analysis and installation at the time of the class that is devoted to applying and practicing what has been learned at home through the learning resources available to him, and this is what distinguishes it from the traditional way in which it is practiced The learner applies what he has studied at home alone without interacting with his colleagues or receiving support from the teacher in a way that does not guarantee his access to the higher levels of knowledge. (1: 114)

The results of this study are consistent with the study of Nadia Hassan Zaghloul's study (2017), whose results indicated that the proposed program using the inverse education strategy contributed positively to the development of motor skills skills on the device of ground movements in gymnastics for students of the fifth grade of basic education in the Emirates. (7)

Thus, the third hypothesis is validated "There are statistically significant differences between the two dimensions of both the control and the experimental group in the level of some technical skills for beginners in volleyball under consideration in favor of the experimental group."

\section{Conclusions:}

Within the limits of the research objectives and hypotheses, the research sample and the method used, and through the statistical treatments of data, the researcher reached the following conclusions:

1- There are statistically significant differences between the pre and post measurement in the level of some technical skills for beginners in volleyball in favor of the dimensional measurement of the control group.

2- There are statistically significant differences between the pre and post measurement in the level of some technical skills for beginners in volleyball in favor of the dimensional measurement of the experimental group.

3- There are statistically significant differences between the two dimensional measurements of both the control and the experimental group in the level of some technical skills for beginners in volleyball under consideration in favor of the experimental group.

4- The reverse learning method is one of the best learning methods that uses Flipped Learning technology to teach some technical skills in volleyball (under discussion).

Recommendations:

In light of the results of the current research, we recommend the following: 
1- The reverse learning method in teaching and teaching the content of technical skills in volleyball for the skills under discussion for students of the first boys group at the Faculty of Physical Education Mansoura University.

2 - In the event of a comparison between the reverse learning method and the rest of the traditional methods (explanation and model performance) in teaching, it is preferable to use the reverse learning method in teaching and teaching volleyball skills under discussion to students of the first boys group at the Faculty of Physical Education.

3- The necessity of optimal utilization of technological means and devices and merging them with the Flipped Learning method during teaching, which gives the best desired educational results.

4- Carrying out similar studies on different age levels or different sporting activities.

\section{References}

1. Atef Abu Hamid Al-Sharman: Integrated Learning and Reverse Learning, Al-Maysarah Publishing House, Amman, 2015.

2. Brame,Cynthia J.(2013) Flipping the classroom,Vanderbit University For Teaching.From/ http://cft.Vanderbit.edu /guidessub.pages/ flipping-the classroom.

3. Estes. M. D., Ingram, R., \& Liu, J. C. (2014). A review of flipped classroom research, practice, and technologies. International HETL Review, Volume 4, Article.

4. Haitham Atef Hassan Ali: Reverse Learning, Dar Al-Sahab Publishing and Distribution, Cairo, 2017.

5. Johnson, L(2012). Effect of the flipped classroom model on a secondary computer applications course: student and teacher perceptions, questions and student achievement. Ph.D. dissertation, University of Louisville , Louisville, Kentucky

6. Khan, F. \& Bernard, A. (2013). Flipping the higher education classroom: the why, what and how, the spring faculty conference, Saturday, March 2, Metropolitan State University.

7. Nadia Hassan Zaghloul: The effectiveness of the inverted class strategy at the level of learning some technical skills skills in gymnastics for fifth-grade students from basic education in the Emirates, Assiut Journal of Sciences and Arts of Physical Education, Assiut University College of Physical Education, p. 44, 3, $2017 \mathrm{~m}$.

8. Safaa Ahmed Lotfy: The effect of using the inverse class on learning some handball skills for students of the Faculty of 
Physical Education, Tanta University, Ph.D., Faculty of Physical Education, Tanta University, 2018

9. Schell, J. (2013). From flipped classrooms to flipping with peer instruction, Retrieved from http://blog.peerinstruction.net/ 2013/11/ 04/fromflipped-classrooms-to-flipping-with-peer-instruction/

10.Zhou G.\&Jiang X.(2014):The oretical Research and Instruction Design of the Flipped Classroom Applied Mechanics and Materials Vols . 543 . 547 